\title{
The effective radium content and radon exhalation rate in hair dyes samples
}

\author{
A.A. Abojassim ${ }^{1}$, L.A. Najam², D. Naji ${ }^{1}$, T.A. Hussain ${ }^{1}$ \\ ${ }^{1}$ University of Kufa, Collage of Science, Department of Physics, Kufa, Iraq \\ ${ }^{2}$ Department of Physics, College of Science, Mosul University, Mosul, Iraq
}

\section{- Original article}

\author{
*Corresponding author: \\ Dr. Ali Abid Abojassim, \\ Fax: +603 79674146 \\ E-mail: \\ ali.alhameedawi@uokufa.edu.iq \\ Revised: May 2016 \\ Accepted: July 2016 \\ Int. J. Radiat. Res., April 2017; \\ 15(2): 207-211 \\ DOI: 10.18869 / acadpub.ijrr.15.2.207
}

\begin{abstract}
Background: Hair dyes are the important materials widely used by various peoples in Iraq and other countries. The present work investigates the presence of the effective radium content and radon exhalation rate in hair dyes samples. Materials and Methods: Twenty hair dyes samples were collected from Iraqi markets. Sealed can technique using LR-115 type II plastic track detector $s$ has been used in order to measure the effective radium content and radon exhalation rate. Results: The average values of the effective radium content ranges were from $2.30 \pm 0.179 \mathrm{~Bq} / \mathrm{kg}$ to $3.07 \pm 0.254 \mathrm{~Bq} / \mathrm{kg}$ and the average values of radon exhalation rate range of $0.282 \pm 0.019 \mathrm{mBq} / \mathrm{m}^{2}$.day to $0.369 \pm 0.026 \mathrm{mBq} / \mathrm{m}^{2}$.day. Conclusion: The results coincide with the recommended OECD and ICRP's action level. In addition a good correlation was found between the effective radium content and radon exhalation rate in hair dyes samples.
\end{abstract}

Keywords: Hair dyes samples, Radon exhalation rate, effective radium content, Sealed can technique, $L R-115$ type II.

\section{INTRODUCTION}

It is well known that the living organisms are continuously exposed to naturally existed ionizing radiation. The radiation sources include cosmic rays, terrestrial radionuclides in the Earth's crust, water and foods as well as those that normally exist in the human body itself (1). The natural radiation, generally, resulted from the distribution of radionuclides on earth. This in turn cause living organisms to be exposed to radiation risk (2). In this context, uranium is the fundamental source of radium and radon in the soil and rocks. The radioactive radium is solid under allowable conditions of temperature and pressure. It decays to radon giving off $\alpha$-particles followed by gamma rays. The radium's concentration is responsible for that how many atoms of radon are generated. The number of radon atoms emitted from the mineral grains or matter and then entered via the pore spaces depends on; the presence of radium atoms in the grain, the texture, the permeability, temperature and pressure (3-6). Radon concentrations and radium isotope may be exist by different natural material such as soil, plant and other material. The radon may be transferred into human beings by the way of internal or external exposure. Therefore, it motivates us to estimate the radon exhalation rate and the effective radium content in hair dyes samples of common use which collected from the local market. This work is also essential from the viewpoints of health and environmental problems. Hair dyes are cosmetics that are put in contact with the skin. It is containing chemical products which may be risky for health. To ensure that hair dyes contain only safe substances, the European Commission has restricted the use of hair dyes to around 45 chemicals (7). There are many publication have used solid state nuclear track detector to measure natural radioactivity in different materials such as building material, detergent powders, toothpastes and other (8-11). This study aims to identify the action of radionuclides from the natural such as radon 
exhalation rate and the effective radium content in some samples hair dyes from different countries that are available in the Iraqi markets using solid state nuclear track detector (LR-115 Type 2).

\section{MATERIALS AND METHODS}

The radon exhalation rate in terms of mass $\left(\mathrm{E}_{\mathrm{m}}\right)$ and the effective radium content $\left(\mathrm{C}_{\mathrm{Ra}}\right)$ were identified by LR-115 type 2 detectors' passive technique. Twenty samples of hair dyes were taken from several markets in Iraq (table 1). The collection of samples was performed between January 2015 and June 2015.

LR-115 Type-II detectors were placed at the closed top end of a plastic cup (diameter $5 \mathrm{~cm}$ and length $9 \mathrm{~cm}$ ) as shown in figure 2 . The thickness of the used SSNTDs was $12 \mathrm{~mm}$ LR-115 type-II strippable cellulose nitrate films,

Table 1. Samples investigated in this study.

\begin{tabular}{|c|c|c|c|}
\hline No & $\begin{array}{c}\text { Sample } \\
\text { Code }\end{array}$ & Sample Brand & Made Produce \\
\hline 1 & S1 & Lady & Iran \\
\hline 2 & S2 & Majesty & Thailand \\
\hline 3 & S3 & Lana (For Man) & China \\
\hline 4 & S4 & White Sea & China \\
\hline 5 & S5 & Garnier & Poland \\
\hline 6 & S6 & Juxiu (For Man) & China \\
\hline 7 & S7 & Xclusive & China \\
\hline 8 & S8 & Mycolor & Italy \\
\hline 9 & S9 & Valancy & France \\
\hline 10 & S10 & Koleston & Labnan \\
\hline 11 & S11 & Palette & Germany \\
\hline 12 & S12 & Diva & Turkey \\
\hline 13 & S13 & Vita color & Italy \\
\hline 14 & S14 & Beauty & EU \\
\hline 15 & S15 & Lana & China \\
\hline 16 & S16 & Waves & Syria \\
\hline 17 & S17 & Jk ( For Man) & China \\
\hline 18 & S18 & Peacock & China \\
\hline 19 & S19 & Bigen & Japan \\
\hline 20 & S20 & Vatika & India \\
\hline
\end{tabular}

Int. J. Radiat. Res., Vol. 15 No. 2, April 2017 reinforced on a transparent $100 \mathrm{~mm}$ polyester thickness (cellulose acetate) sheet, by the French Kodak Path. Sufficient quantities of hair dyes samples were collected for measuring of radon concentrations. The exposure was completed in each sample within a period of about 60 day. After exposure, the detectors were removed from the dosimeters and etched in $2.5 \mathrm{~N} \mathrm{NaOH}$ solution at $60^{\circ} \mathrm{C}$ for $1.5 \mathrm{~h}$ in a bath with water of constant temperature to reveal the tracks. The tracks recorded on LR-115 detectors were counted using an optical microscope (NOVEL, China) of 40× magnification power with USB 2.0 Camera Application V 2.3 software. Background track density of an unexposed detector has also been counted. The changed track density was at that point earned by deducting the track number on a detector that's unexposed from the exposed one within the current calibration experimentation wanted to confirm ${ }^{222} \mathrm{Rn}$ gas concentration originating from a ${ }^{226} \mathrm{Ra}$ source with $3.3 \mathrm{kBq}$.

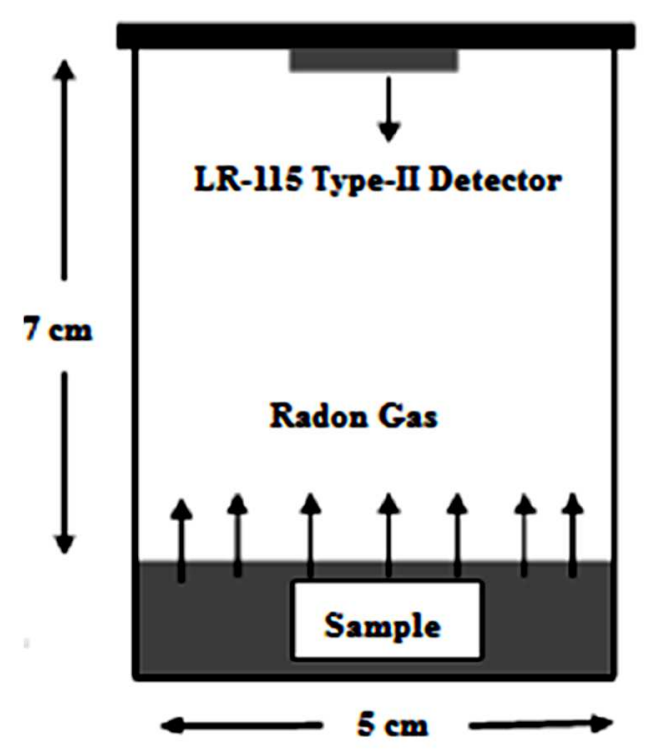

Figure 1. A test tube technique used in the study. 


\section{Calculation of the radon exhalation rate and the effective radium content}

The track densities ( $\rho$ ) can be measured using the equation (1) (12):

$$
\rho=\frac{\sum_{i} N_{i}}{n A}
$$

where, $A$ is the area of the field of view, $N_{i}$ is the total number of tracks and $n$ is the total number of fields of views.

While, the radon concentration $\left(\mathrm{C}_{\mathrm{Rn}}\right)$ was calculated by equation (2) (13):

$$
C_{R n}\left(\frac{B q}{m^{3}}\right)=\frac{N_{o} t_{o} \rho}{\rho_{o} t}
$$

where, $N_{0}, t_{0}$ and $\rho_{0}$ are the activity concentration, the exposure time and the track density for a standard source (Ra-226) respectively, while $t$ and $\rho$ are the exposure time and the track density for hair dyes samples under study.

The effective radium content of the hair dyes samples are often calculated by equation (3) (1415):

$$
C_{R a}\left(\frac{B q}{k g}\right)=\left(\frac{\rho}{k T_{e}}\right)\left(\frac{h A}{M}\right)
$$

where, $\mathrm{h}$ is the distance between the detector and the sample, $A$ is the area of a cross section of the cylinder, $\mathrm{M}$ is the mass of the hair dyes sample, $\mathrm{K}$ is the calibration factor of LR-115 type II detector. It is measured by standard source (Ra-226) which is equal to 0.0217 Track.cm-2/ Bq. $\mathrm{m}^{-3}$.day) and $\mathrm{T}_{\mathrm{e}}$ the effective exposure time.

The effective exposure time $\left(\mathrm{T}_{\mathrm{e}}\right)$ and the exhalation rate in term of mass $\left(\mathrm{E}_{\mathrm{M}}\right)$ were calculated by equations (4) and (5) respectively (15,16):

$$
T_{e}=T-\frac{1}{\lambda\left(1-\theta^{-\lambda T}\right)}
$$

where, $\mathrm{V}$ is the volume of the radon chamber and $\lambda$ is the decay constant for Rn-222.

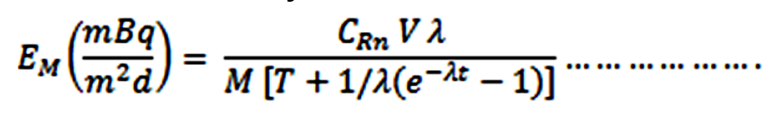

\section{RESULTS AND DISCUSSION}

Table 2 shows the minimum, maximum and average values of effective radium content of twenty samples of hair dyes from various countries. Table 2 shows that, the average of effective radium content in hair dyes samples varies from $(2.30 \pm 0.179) \mathrm{Bq} / \mathrm{kg}$ to $(3.07 \pm 0.254)$ $\mathrm{Bq} / \mathrm{kg}$ (Total average is $2.71 \pm 0.218 \mathrm{~Bq} / \mathrm{kg}$ ). The higher value of effective radium content relatively has been observed in sample S7 (Xclusive, made in china), which denoted the lower than permissible value of $370 \mathrm{~Bq} / \mathrm{kg}$ (17).

The minimum, maximum and average values of radon exhalation Rate in the studied of hair dyes samples are given in table 3. From table 3, it can be seen that the average rate of the radon exhalation varied from $(0.282 \pm 0.019) \mathrm{Bq} /$ $\mathrm{m}^{2}$.day to $(0.369 \pm 0.026) \mathrm{Bq} / \mathrm{m}^{2}$.day (total average is $0.331 \pm 0.023 \mathrm{~Bq} / \mathrm{m}^{2}$.day). To detect connection between the radon exhalation rate and effective radium content, figure 2 shows a graph and detected the correlation coefficient. A good correlation coefficient $\left(\mathrm{R}^{2}=0.75\right)$ has been found between the radon exhalation rate and effective radium content. The effective radium content and radon exhalation rate in the hair dyes samples were low and not significant from the point of view on health hazard.

\section{CONCLUSION}

The effective radium content and the radon exhalation concentration rate have been studied in twenty samples of dye hair that were collected from local Iraqi markets. The highest value of effective radium content was detected in S7 sample, while the lowest value was found in S11 sample. Also, the highest value of exhalation rate was detected in S9 sample while the lowest value was found in S4 sample. The results of this study clearly indicate that the effective radium content and the radon exhalation concentration rate in used samples in present study are mostly below the permissible values limits.

Conflicts of interest: Declared none. 
Table 2. The results of effective radium in hair dyes samples.

\begin{tabular}{|c|c|c|c|c|}
\hline \multirow{2}{*}{ No. } & \multirow{2}{*}{$\begin{array}{c}\text { Sample } \\
\text { code }\end{array}$} & \multicolumn{3}{|c|}{ Effective Radium Content (Bq/kg) } \\
\cline { 3 - 5 } & Minimum & Maximum & Average \\
\hline $\mathbf{1}$ & S1 & 1.93 & 3.46 & 2.79 \\
\hline $\mathbf{2}$ & S2 & 2.44 & 3.94 & 3.17 \\
\hline $\mathbf{3}$ & S3 & 2.57 & 2.8 & 2.64 \\
\hline $\mathbf{4}$ & S4 & 0.93 & 1.03 & 0.98 \\
\hline $\mathbf{5}$ & S5 & 3.86 & 4.87 & 4.40 \\
\hline $\mathbf{6}$ & S6 & 3.4 & 4.94 & 4.22 \\
\hline $\mathbf{7}$ & S7 & 3.6 & 5.26 & 4.45 \\
\hline $\mathbf{8}$ & S8 & 3.13 & 4.00 & 3.75 \\
\hline $\mathbf{9}$ & S9 & 2.87 & 3.73 & 3.38 \\
\hline $\mathbf{1 0}$ & S10 & 1.73 & 2.87 & 2.43 \\
\hline $\mathbf{1 1}$ & S11 & 1.10 & 1.66 & 1.32 \\
\hline $\mathbf{1 2}$ & S12 & 1.52 & 1.8 & 1.64 \\
\hline $\mathbf{1 3}$ & S13 & 2.63 & 2.91 & 2.77 \\
\hline $\mathbf{1 4}$ & S14 & 2.08 & 2.49 & 2.23 \\
\hline $\mathbf{1 5}$ & S15 & 2.01 & 2.49 & 2.33 \\
\hline $\mathbf{1 6}$ & S16 & 2.35 & 2.77 & 2.57 \\
\hline $\mathbf{1 7}$ & S17 & 1.6 & 2.87 & 2.23 \\
\hline $\mathbf{1 8}$ & S18 & 2.01 & 2.54 & 2.29 \\
\hline $\mathbf{1 9}$ & S19 & 2.08 & 2.42 & 2.24 \\
\hline $\mathbf{2 0}$ & S20 & 2.21 & 2.63 & 2.39 \\
\hline $\mathbf{A v e r a g e \pm S D ~}$ & $\mathbf{2 . 3 0 \pm 0 . 1 7 9}$ & $\mathbf{3 . 0 7} \pm \mathbf{0 . 2 5 4}$ & $\mathbf{2 . 7 1 \pm 0 . 2 1 8}$ \\
\hline & & & & \\
\hline
\end{tabular}

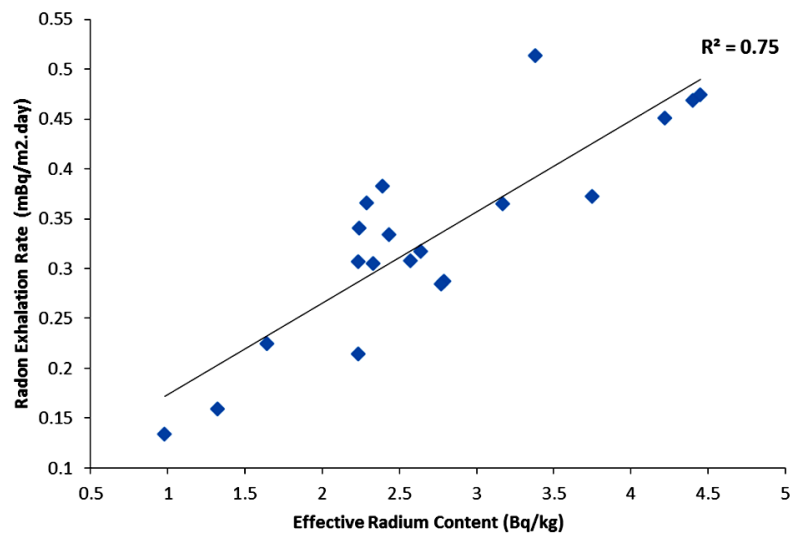

Figure 2. Correlation between the effective radium content and radon exhalation Rate in samples under study.
Table 3. Shows the results of radon exhalation rate in hair dyes samples.

\begin{tabular}{|c|c|c|c|c|}
\hline \multirow{2}{*}{ No. } & \multirow{2}{*}{$\begin{array}{c}\text { Sample } \\
\text { code }\end{array}$} & \multicolumn{3}{|c|}{ Radon Exhalation Rate $\left(\mathrm{mBq} / \mathrm{m}^{2}\right.$.day) } \\
\hline & & Minimum & Maximum & Average \\
\hline 1 & S1 & 0.199 & 0.265 & 0.287 \\
\hline 2 & S2 & 0.281 & 0.454 & 0.365 \\
\hline 3 & S3 & 0.301 & 0.336 & 0.317 \\
\hline 4 & S4 & 0.128 & 0.144 & 0.134 \\
\hline 5 & S5 & 0.412 & 0.52 & 0.469 \\
\hline 6 & S6 & 0.364 & 0.527 & 0.451 \\
\hline 7 & S7 & 0.384 & 0.561 & 0.474 \\
\hline 8 & S8 & 0.311 & 0.404 & 0.372 \\
\hline 9 & S9 & 0.435 & 0.567 & 0.5135 \\
\hline 10 & S10 & 0.237 & 0.394 & 0.334 \\
\hline 11 & S11 & 0.133 & 0.199 & 0.159 \\
\hline 12 & S12 & 0.209 & 0.247 & 0.225 \\
\hline 13 & S13 & 0.27 & 0.300 & 0.285 \\
\hline 14 & S14 & 0.285 & 0.342 & 0.307 \\
\hline 15 & S15 & 0.263 & 0.326 & 0.305 \\
\hline 16 & S16 & 0.282 & 0.332 & 0.308 \\
\hline 17 & S17 & 0.153 & 0.275 & 0.214 \\
\hline 18 & S18 & 0.322 & 0.407 & 0.366 \\
\hline 19 & S19 & 0.316 & 0.367 & 0.341 \\
\hline 20 & S20 & 0.354 & 0.421 & 0.383 \\
\hline \multicolumn{2}{|c|}{ Average $\pm S D$} & $0.282 \pm 0.019$ & $0.369 \pm 0.026$ & $0.331 \pm 0.023$ \\
\hline
\end{tabular}

\section{REFERENCES}

1. UNSEAR (2000) Sources, effects and risks of ionizing. United Nations, New York.

2. WHO (2005) Radon and cancer, fact sheet 291.

3. Fleischer RL (1980) Isotopic disequilibrium of uranium: Alpha - recoil damage and preferential solution effects. Science, 207: 979-981.

4. Tanner $A B(1980)$ Radon migration in the ground: A supplementary review. In The Natural Radiation Environment III. (Eds. T.F. Gesell and W.M. Lowder), National Technical Information service, Springfield, VA. CONF-780422: 50-56.

5. Fleischer RL (1992) Alpha-recoil damage and solution effects in minerals: Isotopic disequilibrium and radon release. Geochemical et Cosmochimica Acta, 46: 2191-2201.

6. Anderson P, Clavensjo B, Akerblom G (1983) The effect of the ground on the concentration of radon and gamma radiation indoors. Swedish Council for Building Research, 9: 1-442.

7. Chan A and Kung S (2006) Hair colorant technology advances further. Personal Care Magazine, October 23, 2006, 
11-16.

8. Hashim AK and Najam LA (2015) Measurement of uranium concentrations, radium content and radon exhalation rate in Iraqi building materials samples. International Journal of Physics, 3(4): 150-164.

9. Abojassim AA, Shaymaa AK, Faeq AM (2014) Radon of concentrations measurement in some types of toothpastes available in the Iraqi markets. Journal of Babylon University/Pure and Applied Sciences, 22(7): 1967-1972.

10. Naom HA (2002) Determining of uranium in toothpaste by using CR-39 detector. M.Sc. Thesis, College of Science, Mosul University, Iraq.

11. Hashim AK and Najam Laith A (2015) Alpha radioactivity in various brands of Rice in Iraqi market. International Journal of Environmental Monitoring and Protection, 2(5): $70-$ 75.

12. Nisar A, Mohamad S, Sohail AK, Tabassum N, Sajjad A, Muhammad R (2014) Measurement of radon exhalation rate, radium activity and annual effective dose from bricks and cement samples collected From Dera Ismail Khan.
American Journal of Applied Science, 11(2): 240-247.

13. Mayya YS, Eappen KP, Nambi KS (1998) Methodology for mixed field inhalation in monazite areas using a twin-cup dosimeter with three-track detector. Radiation Protection Dosimetry, 77: 177-184.

14. Mahur AK, Khan MS, Naqvi AH, Prasad R, Azam A (2008) Measurement of effective radium content of sand samples collected from Chhatrapur beach, Orissa, India using track etch technique. Radiation Measurement, 43: 520-522.

15. Khan MS, Zubair M, Verma D, Naqvi AH, Azam A, Bhardwaj MK, (2011) The study of door radon in the urban dwellings using plastic track detectors. Environmental Earth Sciences, 63: 279-282.

16. Azam A, Naqvi AH, Srivastava DS (1995) Radium concentration and radon exhalation measurements using LR-115 type II plastic track detector. Nuclear Geophysics, 9(6): 653-657.

17. OECD (1979) Report by a group of experts of the OECD Nuclear Energy Agency, Paris, France. 
